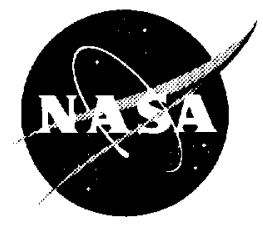

\title{
A Magnetic Suspension and Excitation System for Spin Vibration Testing of Turbomachinery Blades
}

Dexter Johnson, Gerald V. Brown, and Oral Mehmed Lewis Research Center, Cleveland, Ohio

Prepared for the 39th Structures, Structural Dynamics and Materials Conference sponsored by AIAA, ASME, ASCE, AES, and ASC

Long Beach, California, April 20-23, 1998

National Aeronautics and

Space Administration

Lewis Research Center 
Available from

NASA Center for Aerospace Information 800 Elkridge Landing Road Linthicum Heights, MD 21090-2934

Price Code: A03
National Technical Information Service 5287 Port Royal Road Springfield, VA 22100

Price Code: A03 


\title{
A MAGNETIC SUSPENSION AND EXCITATION SYSTEM FOR SPIN VIBRATION TESTING OF TURBOMACHINERY BLADES
}

\author{
Dexter Johnson, ${ }^{*}$ Gerald V. Brown, ${ }^{\dagger}$ and Oral Mehmed ${ }^{\ddagger}$ \\ National Aeronautics and Space Administration \\ Lewis Research Center \\ Cleveland, Ohio 44135
}

\begin{abstract}
The Dynamic Spin Rig (DSR) is used to perform vibration tests of turbomachinery blades and components under spinning conditions in a vacuum. A heteropolar radial active magnetic bearing was integrated into the DSR to provide noncontact magnetic suspension and mechanical excitation of the rotor to induce turbomachinery blade vibrations. The magnetic bearing replaces one of the two existing conventional radial ball bearings. Prior operation of the DSR used two voice-coil type linear electromagnetic shakers which provided axial excitation of the rotor. The new magnetic suspension and excitation system has provided enhanced testing capabilities. Tests were performed at high rotational speeds for longer duration and with higher vibration amplitudes. Some characteristics of the system include magnetic bearing stiffness values up to $60000 \mathrm{lb} / \mathrm{in}$., closed loop control bandwidth around $500 \mathrm{~Hz}$, and multidirectional radial excitation of the rotor. This paper reports on the implementation and operation of this system and presents some test results using this system.
\end{abstract}

\section{Introduction}

Today's turbomachinery components have extensive testing requirements and therefore there is a need to provide enhanced testing capabilities (Refs. 2 and 3 ). Rotating components are expected to be used at very high rotational speeds, have extended life, and have better static and dynamic properties. The Dynamic Spin Rig (DSR) (see Fig. 1) is used to perform research on turbomachinery blades and components under spinning conditions by rotating them in a vacuum chamber (Ref. 1). During rotation the rotor can be vibrated by using two voice-coil type linear electromagnetic shakers that apply axial forces to the rotor. Dynamic measurements are obtained yielding the blade's natural frequencies. The current rotational speed in the DSR is limited due to heating problems with the mechanical bearings.

\footnotetext{
*Research Engineer, member AIAA.

${ }^{\dagger}$ Senior Research Engineer.

¥Research Engineer, member ASME.
}

Additionally, the life of the mechanical bearing is limited. The existing excitation system is limited in the excitation energy it can provide and it can only excite in one plane.

As an alternative to the existing excitation system, a radial active magnetic bearing has been incorporated into the rig to provide magnetic excitation. It also replaces the lower mechanical bearing thereby providing magnetic suspension. Magnetic suspension (Refs. 4 and 5) provides no physical contact at the support position which eliminates heating due to mechanical contact. Mechanical life is substantially extended. Increased flexibility in excitation orientation (direction and phasing) is achieved. Additionally, the magnetic bearing provides active control of stiffness and damping at the point of action. All of these features enable more useful testing to be performed.

\section{The Dynamic Spin Rig}

The DSR provides experimental data for evaluation of vibration analysis methods for rotating systems. Bladed rotors up to $81 \mathrm{~cm}$ ( $32 \mathrm{in}$.) in diameter can be spun to $20000 \mathrm{rpm}$ by a speed regulated air motor. Before installation of the magnetic bearing, electromagnetic shakers were primarily used to apply oscillatory axial forces to the rotor shaft through a thrust bearing. Strain gages, accelerometers, and optical blade-tip vibration sensors provide blade vibration signals.

Figure 2 is a cutaway drawing of the rig with two mechanical bearings supporting the rotor. Shown are the vacuum tank, the air motor drive, two electromagnetic shakers, a multiblade rotor (with a vertical axis of rotation), a 100-channel slipring assembly (which is located at the bottom of the rotor and is used to take signals from the rotor), and an indication of the optical probe system for blade-tip observation. The vacuum (down to 0.02 psia) reduces the torque required to drive the disk and renders aerodynamic effects negligible.

\footnotetext{
Copyright (O) 1998 by the American Institute of Aeronautics and Astronautics, Inc. No copyright is asserted in the United States under Title 17, U.S. Code. The U.S. Government has a royalty-free license to exercise all rights under the copyright claimed herein for Governmental Purposes. All other rights are reserved by the copyright owner.
} 
The two $220-\mathrm{N}$ (50-lbf) shakers move the shaft by acting on the outer race of a thrust bearing. The shakers are operated in phase to provide axial excitation and out of phase to produce a moment on the shaft. Shaft motion is permitted because the rotor bearings are mounted on rubber supports. These supports introduce damping into all modes that couple to axial or transverse motion of the shaft.

The original design of the DSR has the shaft supported by two bearings. There is a bearing at the top and bottom end of the shaft and the blade disk is between the bearings. The bearings are deep groove ball type with grease packing and phenolic cages. A current study has concluded that the rig should be able to run at $10000 \mathrm{rpm}$ without exceeding the recommended DN limit of the bearings. However, running at $15000 \mathrm{rpm}$ is not recommended. The rig has been operated up to $20000 \mathrm{rpm}$ but only for short times. The bearings heat up during operation and a temperature of $220^{\circ} \mathrm{F}$ is used to limit duration at high speeds. When this temperature is reached, the speed of the rig is reduced and the bearings allowed to cool down.

The new magnetic suspension and excitation system involves using a single radial heteropolar active magnetic bearing to replace the lower mechanical bearing. In Fig. 3, the magnetic bearing is shown installed in the rig. This new system adds additional spin vibration testing capabilities to the rig. Details of the new system will be presented in a later section.

\section{Magnetic Suspension and Excitation}

\section{Magnetic Bearing}

The active magnetic bearing is a 4-pole (with 3 legs/ pole existing as an artifact of a previously fabricated stator stamping for a motor) heteropolor type (see Fig. 4). Each pole has 160 coil tums. Its outer diameter is 4.7 in. It is operated using a maximum of $4 \mathrm{~A}$ /coil. Measurements have produced stiffness values up to $60000 \mathrm{lb} / \mathrm{in}$. The nominal radial gap distance is 0.020 in. with a typical operating radial shaft excursion of about 0.005 in. The magnetic bearing system bandwidth, including computer controller, power amplifiers, etc., is about $500 \mathrm{~Hz}$.

\section{Control System}

The control system uses proportional-derivative (PD) control implemented using Turbo Pascal programming language on a 486-PC. This control system allows modification of magnetic bearing parameters such as stiffness and damping. Figure 5 shows the control system block diagram. It includes all of the excitation and suspension elements which represent the system. The controller has two primary components. One component provides the magnetic bearing suspension and the other provides the excitation. Gains can be programmed for various operating conditions.

\section{System Dynamics}

The force, $F$, generated by one pole of an electromagnet can be shown to be given by the following equation:

$$
F=-\frac{\mu_{0} N^{2} A}{4} \frac{i^{2}}{x_{g}^{2}}
$$

where $i$ is the current in the coil, $N$ is the number of coil turns, $A$ is the pole face area, $x_{g}$ is the gap distance, and $\mu_{0}$ is the permeability of free space.

The force in Eq. (1) is attractive and increases as the gap decreases. This attractive force produces an unstable system for an open loop magnetic bearing configuration. The net force produced by an opposing pair of identical electromagnets on a single axis is the sum of the forces produced by each electromagnet, taking into account the sign convention. The net force, $F_{n}$, is obtained using the following equation:

$$
F_{n}=Z\left[\frac{i_{1}^{2}}{x_{g 1}^{2}}-\frac{i_{2}^{2}}{x_{g 2}^{2}}\right]
$$

where the subscripts indicate an association with a particular magnet, and

$$
Z=\frac{\mu_{0} N^{2} A}{4}
$$

Conventional magnetic bearing practice linearizes the force-current relationship by using a bias current along with a superimposed control current. In order to obtain a linear relation between force and control current we express the currents $i_{1}$ and $i_{2}$ in the opposing coils as:

$$
i_{1}=i_{b}+i_{c}
$$

and

$$
i_{2}=i_{b}-i_{c}
$$

where $i_{b}$ is the bias current and $i_{c}$ is the perturbation or control current. Generally, the bias current is chosen to be equal to one-half the maximum allowable current. Next we express each gap in terms of the nominal gap $x_{0}$ and the deviation $x$ from this nominal value caused by the rotor displacement:

$$
x_{g 1}=x_{0}-x
$$


and

$$
x_{g 2}=x_{0}+x
$$

Combining Eqs. (4) to (7) and (2) yields:

$$
F_{n}=Z\left[\frac{\left(i_{b}+i_{c}\right)^{2}}{\left(x_{0}-x\right)^{2}}-\frac{\left(i_{b}-i_{c}\right)^{2}}{\left(x_{0}+x\right)^{2}}\right]
$$

For $x=0$, we can simplify the force equation to involve only $i_{c}$ as a variable:

$$
F_{n}=\frac{Z}{x_{0}^{2}}\left[\left(i_{b}+i_{c}\right)^{2}-\left(i_{b}-i_{c}\right)^{2}\right]
$$

This further simplifies to a linear relationship between force and control current that can be used to implement control commands based on classical linear control theory:

$$
F_{n}=\frac{4 Z i_{b}}{x_{0}^{2}} i_{c}
$$

In order to find the change in force due to a change in position (position stiffness) and the change in force due to a change in current (current stiffness) it is necessary to take the derivative of the force with respect to the variable of interest. Using Eq. (8), the position stiffness evaluated about $x=0$ and $i_{c}=0$ is:

$$
K_{x}=\left.\frac{\partial F_{n}}{\partial x}\right|_{x=0, i_{c}=0}=\frac{4 Z i_{b}^{2}}{x_{0}^{3}}
$$

and the current stiffness evaluated at $x=0$ and $i_{c}=0$ (from Eq. (10)) is:

$$
K_{i}=\left.\frac{\partial F_{n}}{\partial i}\right|_{x=0, i_{c}=0}=\frac{4 Z i_{b}}{x_{0}^{2}}
$$

Now we have a linear relationship between force and control current:

$$
F_{n}=K_{x} x+K_{i} i_{c}
$$

This linearized force equation is generally used for linear control development even though the assumptions that were made are occasionally violated in practice.

For proportional-derivative (PD) feedback control the following relation is used:

$$
i_{c}=-\left(K_{p} x+K_{d} \dot{x}\right)
$$

where $K_{p}$ is the proportional control gain and $K_{d}$ is the derivative control gain.

Consequently, for a rigid rotor, an equivalent lumped mass model, $m_{e q}$, of the rotor can be used and the dynamics of the system would become:

$$
m_{e q} \ddot{x}=F_{n}
$$

Substituting Eq. (14) into Eq. (13) and Eq. (14) into Eq. (15) and simplifying, the following is obtained:

$$
m_{e q} \ddot{x}+K_{i} K_{d} \dot{x}+\left(K_{i} K_{p}-K_{x}\right) x=0
$$

Equation (16) represents the suspension system. To include the excitation portion we can add an excitation variable, $i_{e x}$, to Eq. (14) to get:

$$
i_{c}=-\left(K_{p} x+K_{d} \dot{x}\right)+i_{e x}
$$

The resulting system dynamics becomes:

$$
m_{e q} \ddot{x}+K_{i} K_{d} \dot{x}+\left(K_{i} K_{p}-K_{x}\right) x=F_{e x}
$$

where the excitation force, $F_{e x}$, is given by:

$$
F_{e x}=K_{i} i_{e x}
$$

Finally, if we define

$$
c_{e q}=K_{i} K_{d}
$$

and

$$
k_{e q}=K_{i} K_{p}-K_{x}
$$

then the final dynamic equation becomes:

$$
m_{e q} \ddot{x}+c_{e q} \dot{x}+k_{e q} x=F_{e x}
$$

\section{Magnetic Suspension}

The magnetic bearing operates not only as an exciter but as a fully functioning magnetic bearing. Magnetic suspension provides no physical contact at the support position which eliminates heating due to mechanical contact. Mechanical life is substantially extended. Increased flexibility in how the excitation is applied (direction and phasing) is achieved. The magnetic bearing supports the shaft at the lower end which was previously supported by 
a mechanical bearing. The magnetic bearing provides active control of stiffness and damping at the point of action. In order to determine what combination of gains are useful and produce stable operation, a stability map was obtained experimentally by observing and recording what gain combinations produced instability. These gains are plotted to show a stability surface under which stable operation of the system is achieved (see Fig. 6). A frequency domain representation of the system's dynamic characteristic gives another perspective of the system. A transfer function between the excitation signal and the shaft position signal gives a spectral profile that indicates how well we can transmit energy to the system (see Fig. 7; $K$ is the keyboard value of control stiffness and $D$ is the keyboard value of control damping).

Testing yielded successful magnetic bearing operation for rotational speeds up to $9000 \mathrm{rpm}$, in a vacuum, with control gains producing stiffness up to $60000 \mathrm{lbs} / \mathrm{in}$. The success of the initial work has led to the design and intended implementation of a full magnetic suspension system. The full magnetic support will enable longer run time at higher speeds and larger vibration amplitudes for rotating blades.

\section{Excitation Operation}

In Fig. (8), a schematic of the reference coordinates is shown. The $x-y$ axes are fixed and are representative of the stator frame of reference. The radius vector, $r$, is a representative vector of a fixed location on the moving shaft. This can be associated with the planar location of a set of blades on the shaft. The excitation force vector, $F_{e x}$, is the excitation force produced by the magnetic bearing which can be oriented in any radial direction. $\theta$ and $\phi$ are the vector angles for the radius vector and the excitation force vector, respectively.

The excitation signal can have a variety of forms. It can be a sinusoidal signal of single frequency, random, broadband noise, or any general signal generated by a signal generator or a feedback control law in the control system. For most conditions the excitation has the following form:

$$
F_{e x}=F_{0} \sin (\psi r)
$$

where $F_{0}$ is the excitation signal amplitude and $\psi$ is the excitation frequency. The force resolved onto the $x-y$ axes yields:

$$
\begin{aligned}
F_{e x_{x}}=F_{e x} \cos (\phi)=F_{0} \sin (\psi t) & \cos (\phi) \\
= & F_{0} \sin (\psi t) \cos (\eta t)
\end{aligned}
$$

$$
\begin{aligned}
F_{e x y}=F_{e x} \sin (\phi)=F_{0} \sin (\psi t) & \sin (\phi) \\
= & F_{0} \sin (\psi t) \sin (\eta t)
\end{aligned}
$$

where the sub-subscripts indicates the associated reference axis and the excitation angular frequency, $\eta$, is given by:

$$
\eta=\dot{\phi}
$$

The rotational speed of the shaft, $\omega$, is given as follows:

$$
\omega=\dot{\theta}
$$

The magnetic bearing exciter has several modes of shaking the rotor to produce blade vibrations. The differences between the modes are due to the radial orientation, phasing, and frequency of the applied force. There are two primary modes of operation. One mode produces an excitation force with a fixed orientation with respect to the stator, i.e. $\phi$ is constant, which is called the stator-fixed mode. The other mode produces an excitation force with a fixed orientation with respect to the rotor, i.e. $\phi$ is not constant, which is called the rotor-fixed mode. For each mode of operation, the shaft may or may not be rotating. For nonrotating tests, where $\theta$ is constant, the stator fixed mode allows the force to be set at a desired orientation that may be optimal for large deflections. An example of this would be for a two-bladed test article in which the blades were positioned to lie coplanar to the plane made by the radial position vector, $r$, and the shaft vertical axis (see Figs. 8 and 9). For this blade position, the force would best be oriented perpendicular to the blade plane, where $\theta-\phi=(2 n-1) \pi / 2, n=1,2,3 \ldots$, and $\theta=$ const, to produce large amplitude "flapping" vibrations. For rotating tests with the stator-fixed force, $\phi$ can be arbitrary since any setting produces the same vibratory response. The rotorfixed mode produces an excitation force with a fixed orientation with respect to the rotor based upon a onceper-revolution signal. Operating this way for nonrotating tests, using an artificial once-per-revolution signal, allows whirling of the shaft to produce blade vibrations ( $\phi \neq$ const and $\theta=$ const). For rotating tests, the orientation of the excitation force follows the test article as it rotates $(\theta-\phi$ $=$ const, $n=1,2,3 \ldots$, and $\theta \neq$ const). This is an excellent spin test feature. Other modes of operation can be achieved. For any of these modes, sinusoidal or random signals can be used for $F_{e x}$. Typically, one can use random noise to find the blade frequencies and then use a sinusoidal signal to drive at a particular frequency of interest.

Operation of the magnetic bearing as an exciter was successful and compared favorably to the electromagnetic 
shakers. The magnetic bearing can transmit more vibrational energy into the shaft, excite some blade modes to larger amplitudes, and improve flexibility in applying the excitation force in orientation and phasing. A summary of the excitation operation is given in Table $\mathrm{I}$.

\section{Vibration Testing}

Dynamic tests have been performed using this new capability (Ref. 8). Blade like structures (see Fig. 9), provided by the University of California at San Diego, were tested and essential dynamic data was obtained (Ref. 7). Results from the tests indicated that using the new magnetic excitation system was extremely beneficial.

A preliminary investigation was performed using the magnetic bearing system to provide shaft actuation to suppress blade vibrations using blade strain gage feedback. Initial results were favorable and were presented at the High Cycle Fatigue Initiative Workshop - Active Vibration Control/Engine Health Monitoring Session December 10 , 1996. The presentation was titled "Active Control of Blade Vibration Using Magnetic Forcing of Shafts." Two sample frequency response figures are shown in Figs. 10 and 11. In Fig. 10, the mechanical shakers are used for excitation with the magnetic bearing used for blade vibration control. In Fig. 11, the magnetic bearing is used for excitation and control. Comparing Figs. 10 and 11 indicate that for these tests the magnetic excitation transmitted more energy to the blades for the uncontrolled conditions.

\section{$\underline{\text { Summary }}$}

In summary, a single radial active magnetic bearing was integrated into the Dynamic Spin Rig (DSR) to provide vibration excitation. The rig was modified to have the magnetic bearing replace a conventional ball bearing support thereby providing blade vibration excitation, and shaft suspension and control. The implementation of the new system has been outlined and the preliminary operational performance of the magnetic bearing has been assessed, producing favorable results. This work demonstrated the feasibility of using magnetic actuation to enhance structural dynamic testing. Consequently, the system will be converted to an all magnetically supported one, further enhancing its testing capabilities. The magnetic bearings will provide magnetic actuation for excitation and support, increase excitation energy and forceorientation flexibility, allow longer duration at high rotational speeds, and increase test duration (life cycles).

\section{$\underline{\text { References }}$}

1. Brown, G.V., Kielb, R.E., Meyn, E.H., Morris, R.E., Posta, S.J., "Lewis Research Center Spin Rig and Its Use in Vibration Analysis of Rotating Systems." NASA TP-2304, May 1984.

2. Kosmatka, J.B., Lapid, A.J., and Mehmed, O., "Behavior of Spinning Laminated Composite Plates with Initial Twist-Experimental Investigation." Proceedings of the ASME Winter Meeting, November 1992.

3. Kosmatka, J.B., Lapid, A.J., "The Experimental Behavior of Spinning Pretwisted Laminated Composite Plates." Department of Applied Mechanics and Engineering Services, University of California, San Diego. Final Report on a Research Project Funded through NASA Research Grant Number NCC 3-173. Report No. SSRP-93/10.

4. Fleming, D.P., "Magnetic Bearings-State of the Art," NASA TM-104465.

5. Siegwart, R., Vischer, D., Larsonneur, R. Herzog, R., Traxler, A., Bleuler H., Sweitzer, G., "Control Concepts for Active Magnetic Bearings," Proceedings of the International Symposium on Magnetic Suspension Technology, NASA CP-3152, Part 1, 1992, pp. $401-422$.

6. Sinha, A., "On the Design of Magnetic Suspension Systems," ASME International Gas Turbine Conference, Department of Mechanical Engineering, The Pennsylvania State University, University Park, Pa., 16802.

7. Mehmed, O., Kosmatka, J.B., “Damping Experiment of Spinning Composite Plates With Embedded Viscoelastic Material,' Physics and Process Modeling (PPM) and Other Propulsion R\&T, Cleveland, Ohio, May 1, 1997, NASA CP-10193, Volume II.

8. Johnson, D., Mehmed, O., Brown, G.V., "Magnetic Excitation for Spin Vibration Testing," Physics and Process Modeling (PPM) and Other Propulsion R\&T, Cleveland, Ohio, May 1, 1997, NASA CP-10193, Volume II.

TABLE I-SUMMARY OF EXCITATION OPERATION

\begin{tabular}{|l|c|c|c|}
\hline \multicolumn{3}{|c|}{ Operational mode } \\
\hline $\begin{array}{l}\text { Stator-fixed reference } \\
\text { nonrotating shaft } \\
\text { rotating shaft }\end{array}$ & $\begin{array}{l}\text { constant } \\
\text { variable }\end{array}$ & $\begin{array}{l}\text { constant } \\
\text { constant }\end{array}$ & $\begin{array}{l}\text { constant } \\
\text { variable }\end{array}$ \\
\hline $\begin{array}{l}\text { Rotor-fixed reference } \\
\text { nonrotating shaft } \\
\text { rotating shaft }\end{array}$ & $\begin{array}{c}\text { constant } \\
\text { variable }\end{array}$ & $\begin{array}{l}\text { variable } \\
\text { variable }\end{array}$ & $\begin{array}{l}\text { variable } \\
\text { constant }\end{array}$ \\
\hline
\end{tabular}




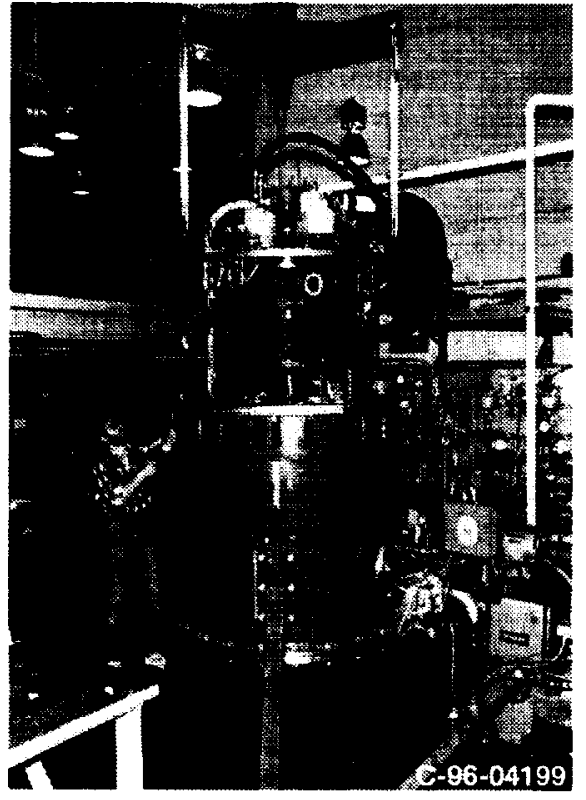

Figure 1.-Dynamic Spin Rig Facility.

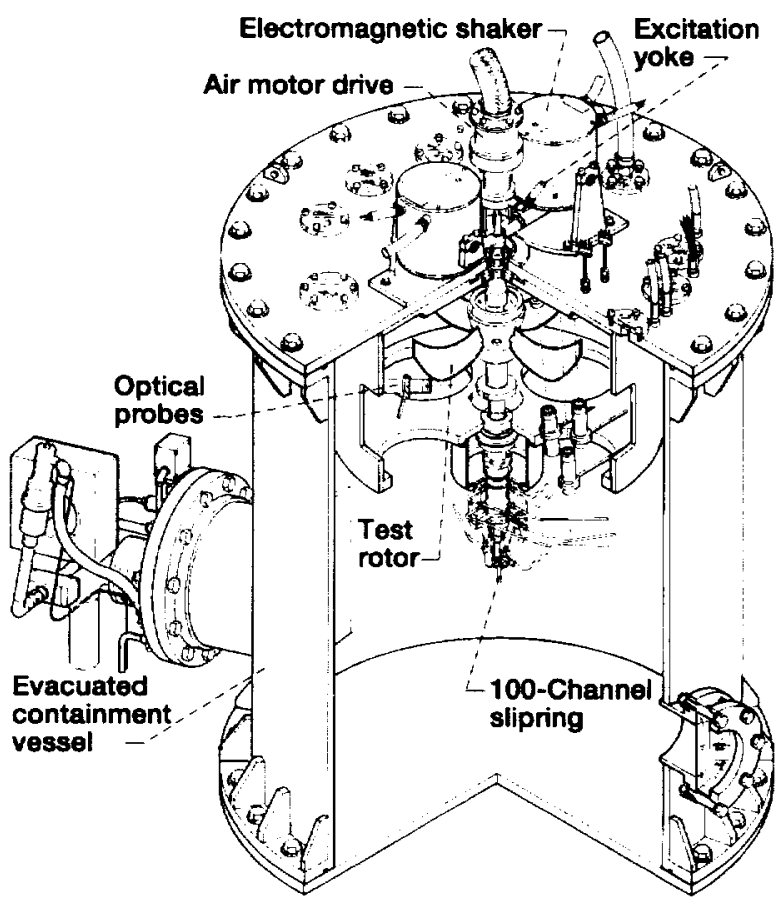

Figure 2.-Cutaway drawing of Dynamic Spin Rig.

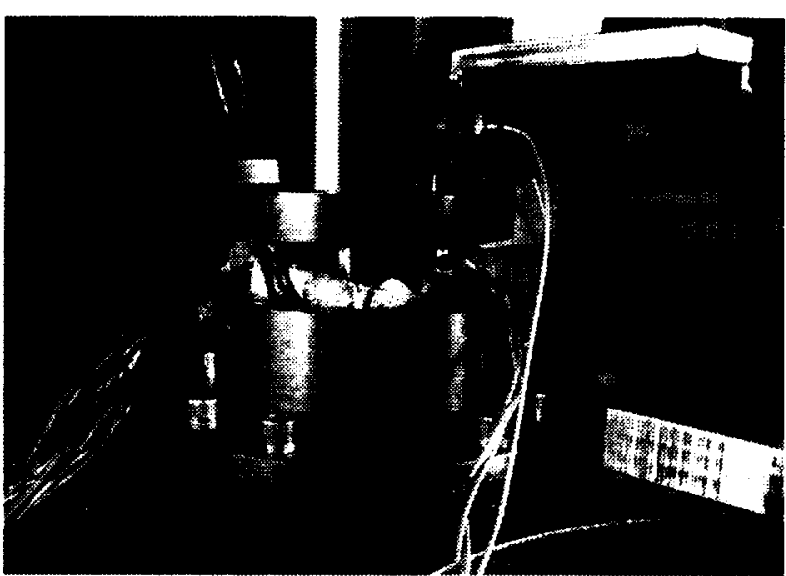

Figure 3.-Magnetic bearing installed in Dynamic Spin Rig.

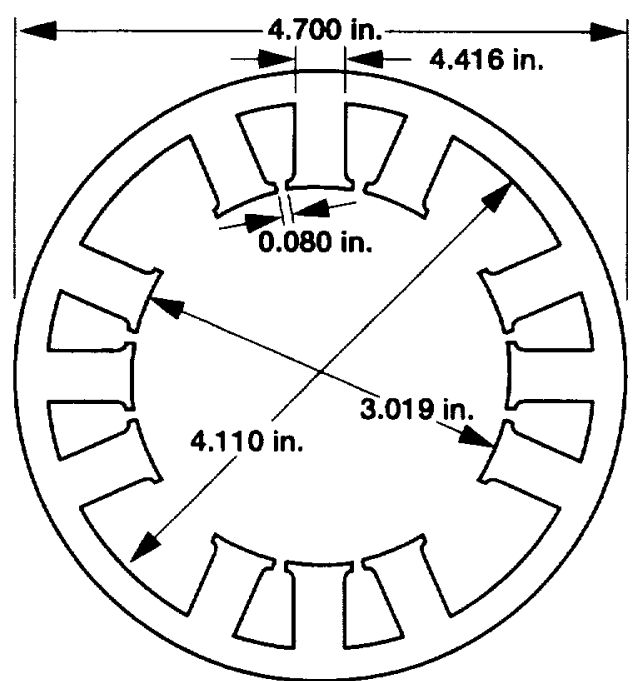

Figure 4.-Magnetic bearing stator laminations.

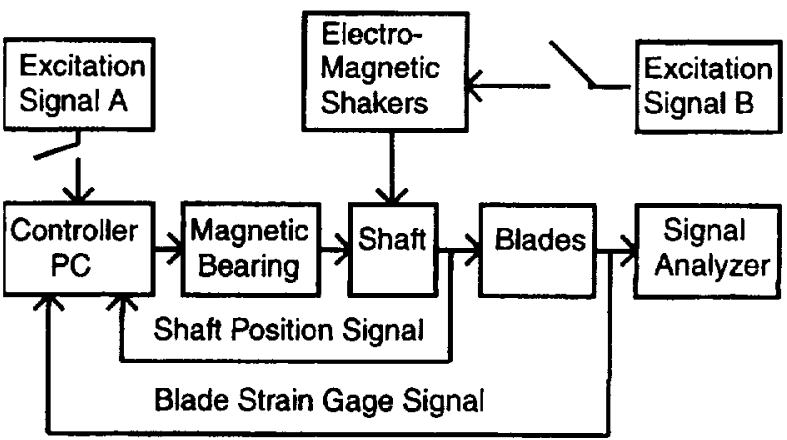

Figure 5.-Block diagram for Dynamic Spin Rig excitation system. 


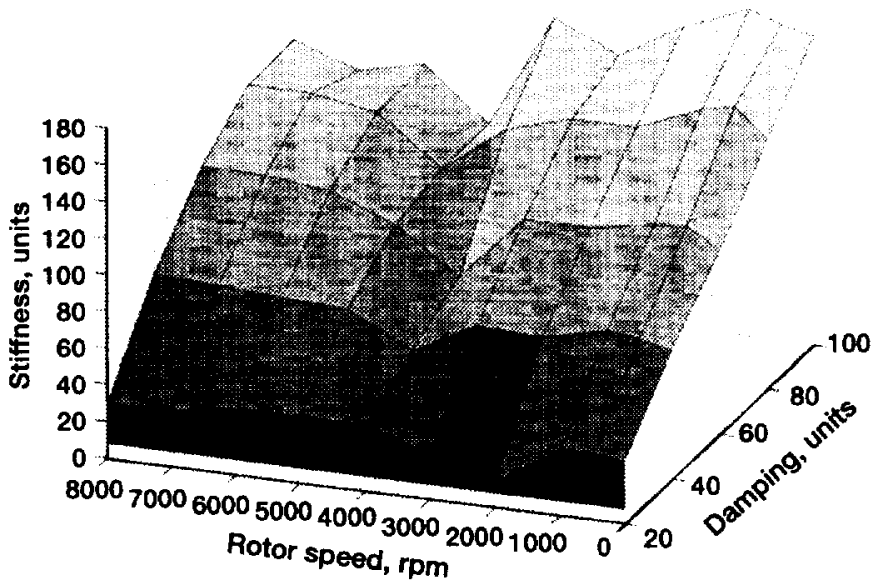

Figure 6.-Dynamic Spin Rig magnetic bearing control system stability limit suface.

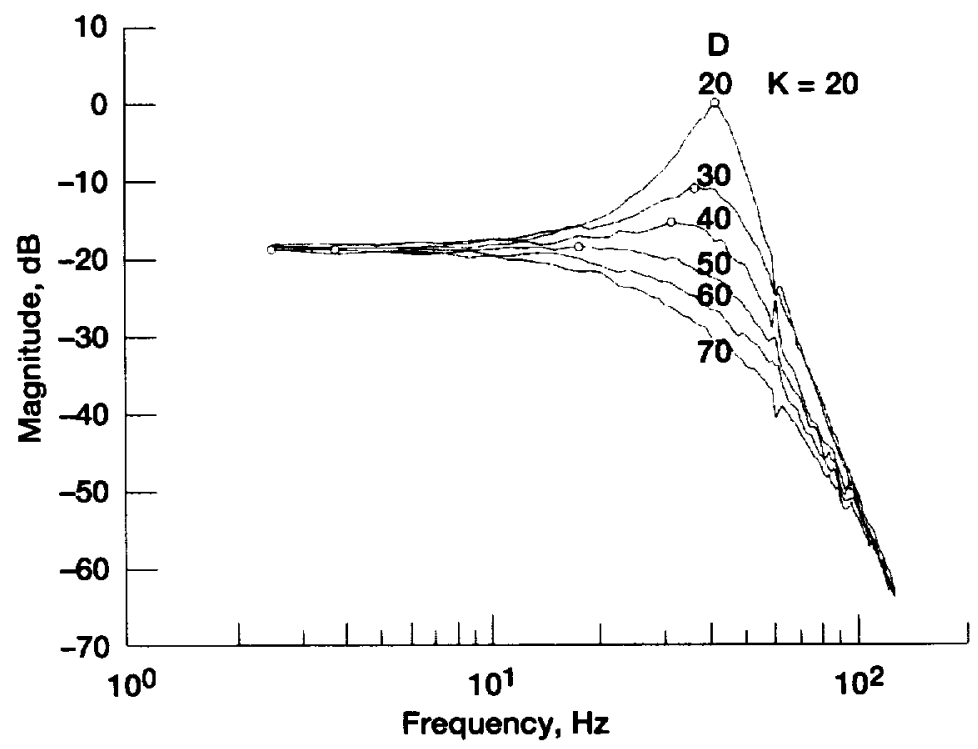

Figure 7.-Dynamic Spin Rig magnetic bearing/rotor transfer function (in vacuum) $-Y$ axis, constant $K$, variable $D$. 


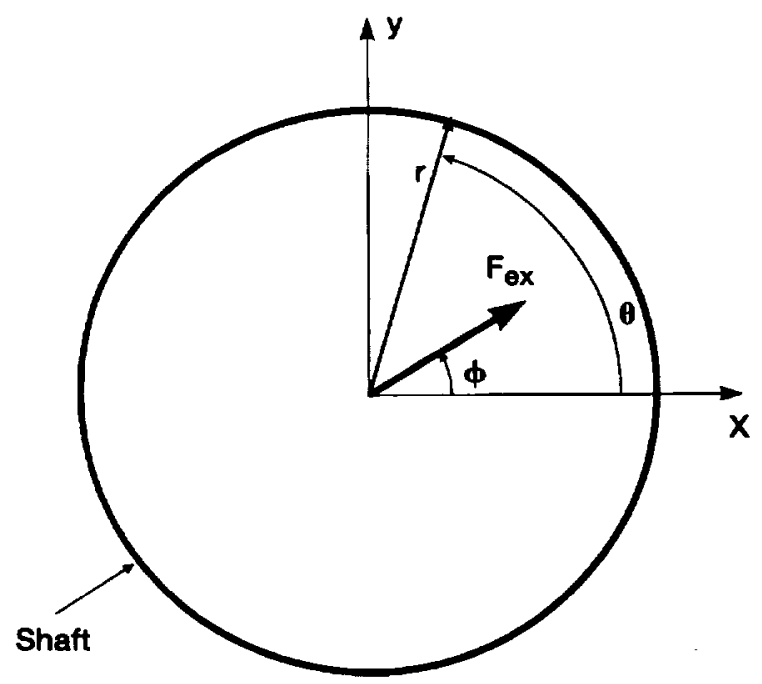

Figure 8. Schematic of top down view of shaft.

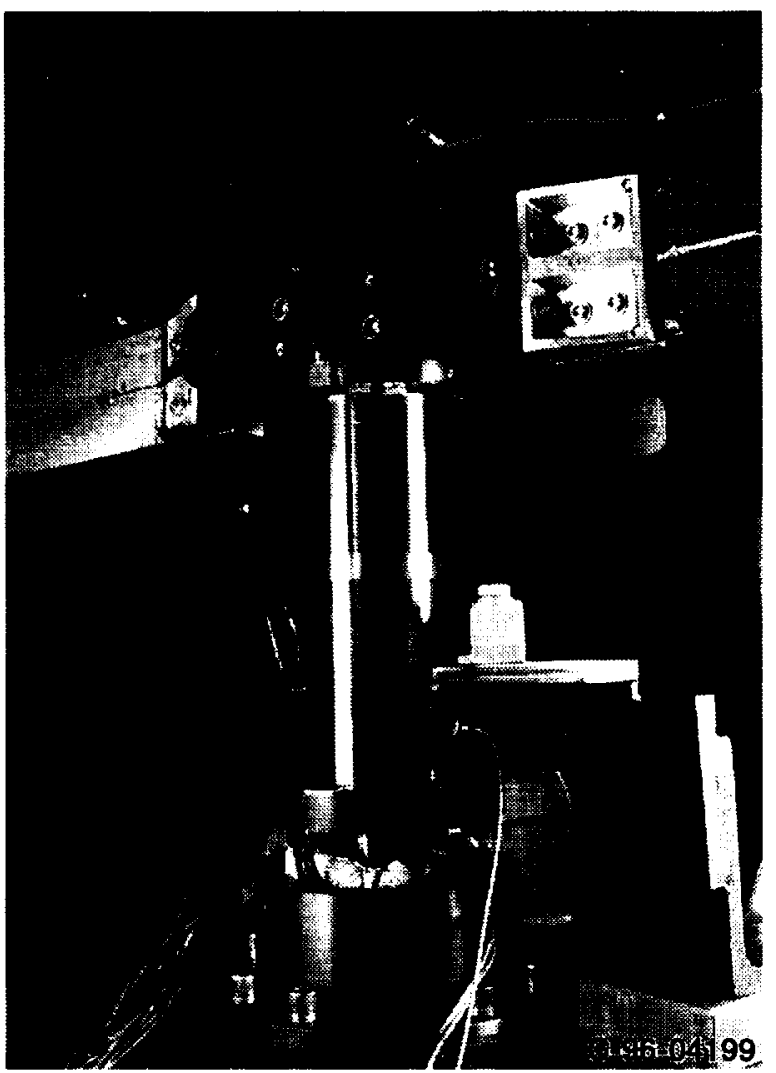

Figure 9.-Viscoelastic damped composite plates in the NASA Dynamic Spin Rig Facility.
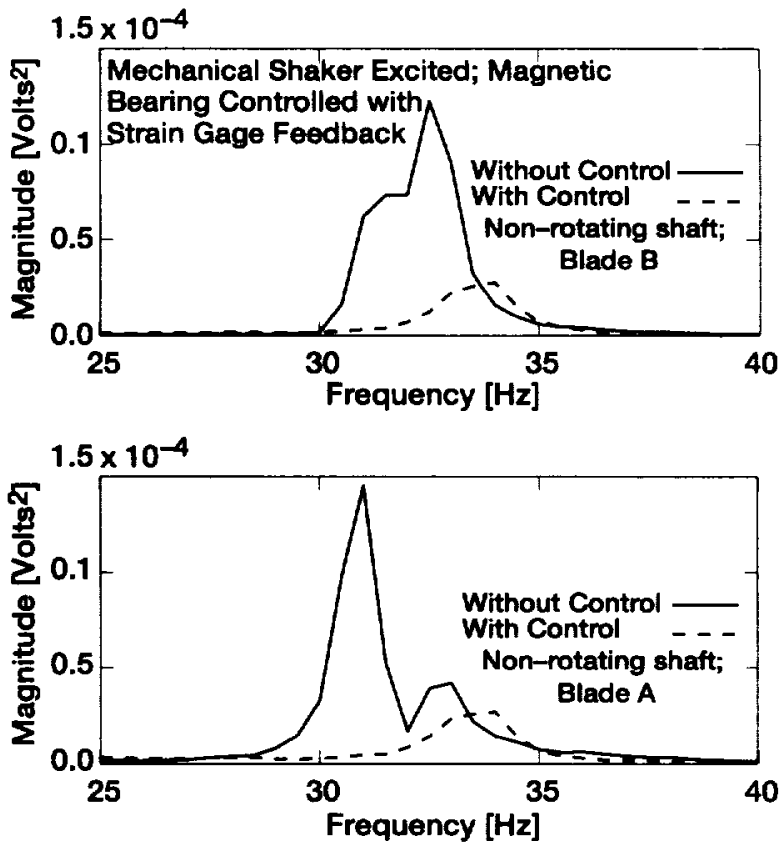

Figure 10.-Power spectral density of flat plates with damping patches.
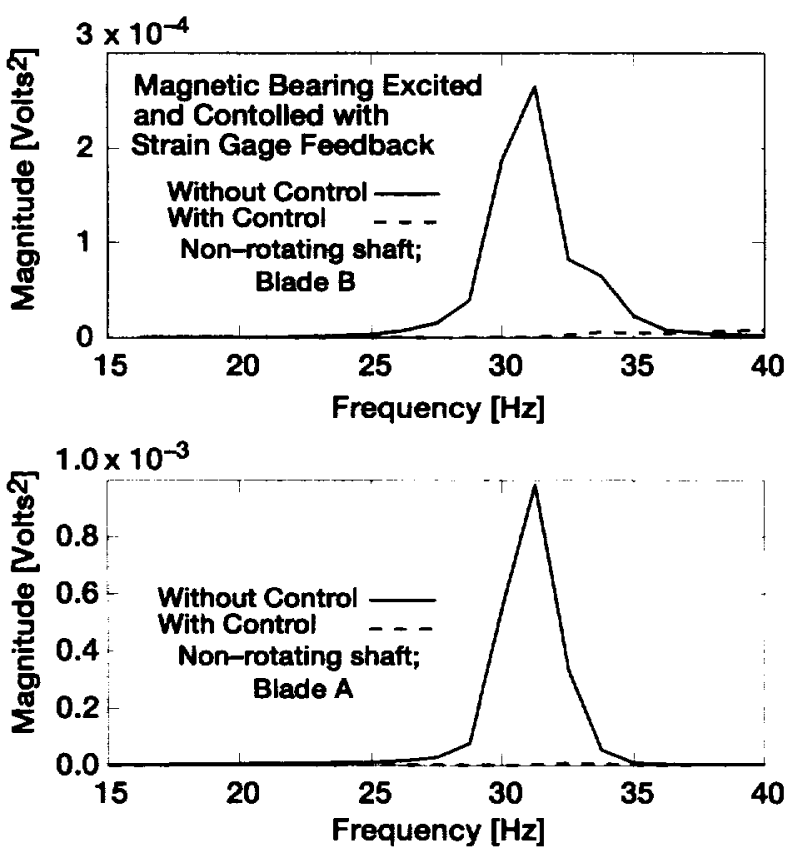

Figure 11.-Power spectral density of flat plates with damping patches. 


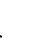




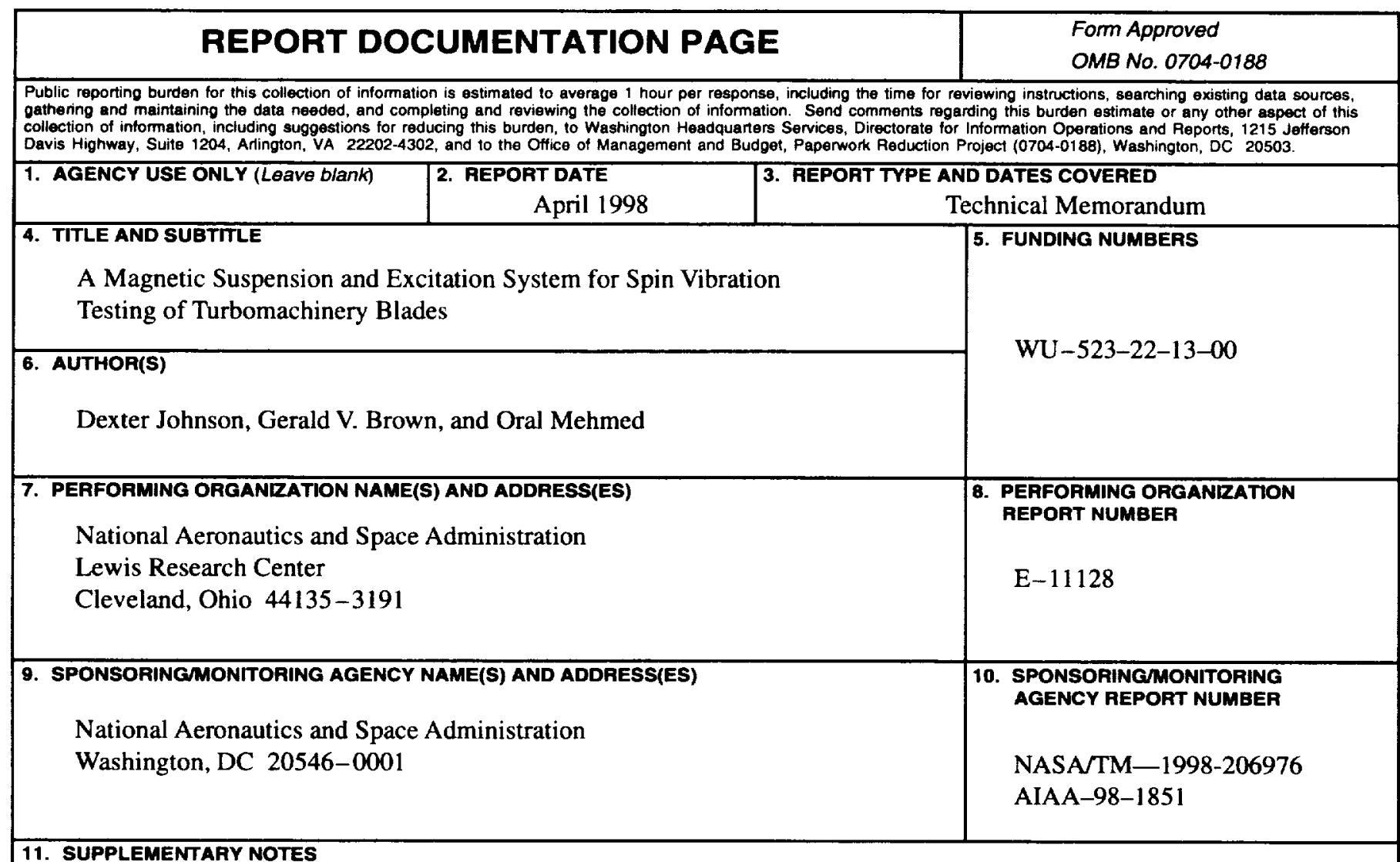

Prepared for the 39th Structures, Structural Dynamics and Materials Conference sponsored by AIAA, ASME, ASCE, AES, and ASC, Long Beach, California, April 20-23, 1998. Responsible person, Dexter Johnson, organization code 5930, (216) 433-6046.

12a. DISTRIBUTION/AVAILABILITY STATEMENT 12b. DISTRIBUTION CODE

Unclassified - Unlimited

Subject Categories: 01 and 09

Distribution: Nonstandard

This publication is available from the NASA Center for AeroSpace Information, (301) 621-0390.

13. ABSTRACT (Maximum 200 words)

The Dynamic Spin Rig (DSR) is used to perform vibration tests of turbomachinery blades and components under spinning conditions in a vacuum. A heteropolar radial active magnetic bearing was integrated into the DSR to provide non-contact magnetic suspension and mechanical excitation of the rotor to induce turbomachinery blade vibrations. The magnetic bearing replaces one of the two existing conventional radial ball bearings. Prior operation of the DSR used two voice-coil type linear electromagnetic shakers which provided axial excitation of the rotor. The new magnetic suspension and excitation system has provided enhanced testing capabilities. Tests were performed at high rotational speeds for longer duration and higher vibration amplitudes. Some characteristics of the system include magnetic bearing stiffness values up to $60,000 \mathrm{lb} . / \mathrm{in}$., closed loop control bandwidth around $500 \mathrm{~Hz}$, and multi-directional radial excitation of the rotor. This paper reports on the implementation and operation of this system and presents some test results using this system.

14. SUBJECT TERMS

Magnetic suspension; Magnetic bearing; Vibration testing; Turbomachinery blades

16. PRICE CODE

$\mathrm{AO3}$

\begin{tabular}{|c|c|c|}
\hline $\begin{array}{c}\text { 17. SECURTY CLASSIFICATION } \\
\text { OF REPORT } \\
\text { Unclassified }\end{array}$ & $\begin{array}{c}\text { 18. SECURITY CLASSIFICATION } \\
\text { OF THIS PAGE } \\
\text { Unclassified }\end{array}$ & $\begin{array}{c}\text { 19. SECURITY CLASSIFICATION } \\
\text { OF ABSTRACT } \\
\text { Unclassified }\end{array}$ \\
\hline
\end{tabular}

NSN 7540-01-280-5500 